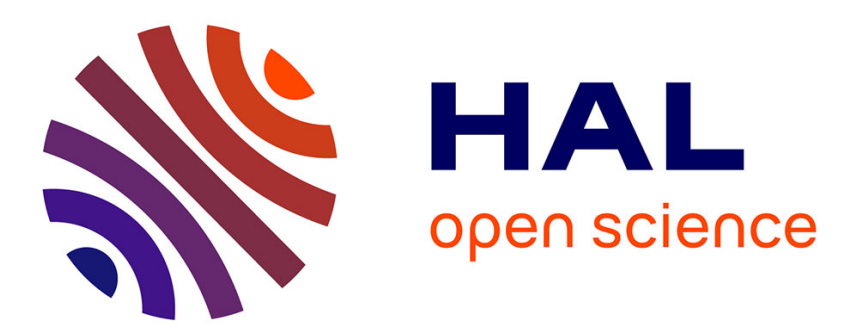

\title{
Safety Climate, Perceived Risk, and Involvement in Safety Management
}

Dongo Rémi Kouabenan, Robert Ngueutsa Ngueutsa, Mbaye Safiétou

\section{To cite this version:}

Dongo Rémi Kouabenan, Robert Ngueutsa Ngueutsa, Mbaye Safiétou. Safety Climate, Perceived Risk, and Involvement in Safety Management. Safety Science, 2015, 77, 10.1016/j.ssci.2015.03.009 . halshs-01425831

\section{HAL Id: halshs-01425831 https://shs.hal.science/halshs-01425831}

Submitted on 10 Jul 2017

HAL is a multi-disciplinary open access archive for the deposit and dissemination of scientific research documents, whether they are published or not. The documents may come from teaching and research institutions in France or abroad, or from public or private research centers.
L'archive ouverte pluridisciplinaire $\mathbf{H A L}$, est destinée au dépôt et à la diffusion de documents scientifiques de niveau recherche, publiés ou non, émanant des établissements d'enseignement et de recherche français ou étrangers, des laboratoires publics ou privés. 


\title{
Safety climate, perceived risk, and involvement in safety management is
}

\author{
Dongo Rémi Kouabenan ${ }^{a, *}$, Robert Ngueutsa ${ }^{a}$, Safiétou Mbaye ${ }^{b}$ \\ ${ }^{a}$ University of Grenoble 2, UFR SHS, Interuniversity Laboratory of Psychology, BP 47, 38040 Grenoble Cedex 09, France \\ ${ }^{\mathrm{b}}$ EDF $R$ \& $D$, Groupe Facteurs Humains, 1 Avenue du Général de Gaulle, 92140 Clamart Cedex, France
}

\section{A R T I C L E I N F O}

\section{Article history:}

Received 17 August 2014

Received in revised form 27 November 2014

Accepted 14 March 2015

\section{Keywords:}

Safety climate

Risk perception

Involvement in safety management

Front-line manager

Supervisor-supervisees social exchange

\begin{abstract}
A B S T R A C T
This article examines the relationship between safety climate, risk perception and involvement in safety management by first-line managers (FLM). Sixty-three FLMs from two French nuclear plants answered a questionnaire measuring perceived workplace safety climate, perceived risk, and involvement in safety management. We hypothesized that a positive perception of safety climate would promote substantial involvement in safety management, and that this effect would be stronger than the perceived-risk effect. We also expected that safety climate dimensions would have a different impact on involvement in safety management. Especially, we expected climate dimensions dealing with safety-related exchanges between managers and their supervisees to be more related to FLMs' involvement in safety management. As expected, perceived risk, as well as safety climate, was related to FLMs' involvement in safety management: the more they perceived risks as probable and serious for their supervisees, the more involved they got in safety management. Similarly, FLMs who perceived a good safety climate in their company reported getting more involved in safety management than did FLMs who perceived a poor safety climate. Moreover, the results showed that safety climate was the key variable because it completely mediated the effect of perceived risk on involvement in safety management. Another important result showed that immediate supervisor encouragement was more influential than senior management views on safety. Furthermore, the fact of being called upon by supervisees on safety issues prompted the FLMs to be more involved in safety management. Possible avenues for improving the involvement of FLMs in safety management are suggested.
\end{abstract}

(c) 2015 Elsevier Ltd. All rights reserved.

\section{Introduction}

Controlling risk is extremely important in all workplaces, particularly in "sensitive" or high-risk industries such as nuclear power. Today it is generally agreed that risk control relies on the active collaboration and involvement of all individuals in the organizational system (executives and managers, developers, whitecollar personnel at all levels, workers, etc.). In this hierarchy, first-line managers (FLMs) - who are in direct contact with operators exposed to risk and are in charge of implementing safety policies - play the most important role in keeping the workplace safe. Yet, these managers play a pivotal role in identifying potentially risky events and practices, whether involving individuals or groups, and also in carrying out safety policies and relaying

\footnotetext{
The present study was commissioned and funded by the French company EDF, a producer/distributor of electricity.

* Corresponding author at: University of Grenoble 2, Laboratory LIP/PC2S, UFR SHS, 1251, Avenue Centrale, BP 47, 38040 Grenoble Cedex 9, France. Tel.: +33 476 825 629; fax: +33 476825665.

E-mail address: Remi.Kouabenan@upmf-grenoble.fr (D.R. Kouabenan).
}

information to higher levels about situations or conditions likely to jeopardize worker safety. More specifically, FLMs must "mediate various organizational priorities, manage multiple logistics that are not always compatible (in terms of deadlines, productivity, service quality), integrate multiple requirements from diverse stakeholders (e.g., from upper management requesting rational operations, from clients expecting satisfaction, from processing itself which must be kept running smoothly), take on the function of translating and summarizing: translating general policies and objectives into operational terms for work teams" (Guillaume and Gillet, 2009, p.13). In sum, FLMs' effectiveness is highly dependent on their ability to respond to various requests and expectations from both their hierarchical supervisors and supervisees, and to spearhead a group dynamic centered on safety that is consistent with organizational goals.

We believe that these requests and expectations act as a set of subjective norms ${ }^{1}$ (Ajzen, 2001) that can shape FLMs' attitudes toward safety. From this angle, studying FLMs' perceptions of safety

\footnotetext{
${ }^{1}$ Perceived social pressure favoring the adoption or non-adoption of a behavior.
} 
could help us understand how committed their supervisors and supervisees think the FLMs are to safety issues, and how committed they actually are to their leadership role in safety matters. Indeed, we think that in order to reinforce FLMs' involvement in safetyrelated actions, it is important to better identify their perceptions in order to see how those perceptions determine their attitudes toward managing safety, which is partly under their responsibility. For example, we know that for middle managers, some of the factors likely to promote a good safety climate within the organization are commitment and involvement, priority given to safety, decentralization of decision-making, positive interactions with workers, and management's humanistic actions and support, etc. (O'Dea and Flin, 2001). Their position as intermediaries between supervisors and supervisees requires FLMs to continuously make adjustments between these two occupational groups.

The present study aims to investigate the factors favoring firstline managers' involvement in managing safety issues. It starts from the idea that this involvement may be related to the perception that FLMs have of the risks to which their coworkers or supervisees are exposed, as well as to their perception of the safety climate that reigns in the organization including their perceptions of the interactions with their senior management and their supervisees. To support our assumptions, we describe in the following paragraphs studies on the relationship between risk perception and safety behaviors as well as between safety climate and prevention practices.

\section{Perceived risk and safety}

Studying the perception of risks by people exposed to them seems to be gaining traction as a way to promote greater involvement in safety-related actions and increase their effectiveness as well (Arezes and Miguel, 2008; Gandit et al., 2009; Gyekye, 2006; Ji et al., 2011; Kuttschreuter, 2006; Kouabenan, 1998, 2009; Kouabenan et al., 2007; Rundmo, 2001; Weinstein et al., 2007; Mbaye and Kouabenan, 2013). Numerous observations and studies attest the link between risk perception and protective behavior. Some cases in point are the "impact on consumption of food-related fears aroused by perceived risks linked to consumption of certain foods or meats (mad cow, listeria in cheese, dioxins in chicken, etc.), and the effects of the September 11, 2001 attacks on air transportation" (Kouabenan, 2006, p. 12). In Kuttschreuter's (2006) study on the link between two perceived food risks (contamination of chicken with salmonella or dioxin) and the behavioral reactions of 280 Dutch participants, the author noted that people who avoided consuming contaminated chicken perceived the risk as very high, saw themselves as quite vulnerable, were highly concerned emotionally, had a strong need for information, and had less confidence in food safety. In the same vein, in a study with 428 American participants, Weinstein et al. (2007) found a link between the perceived risk of catching the flu and the decision to get vaccinated. In a study with 118 commercial pilots of the China Southern Airlines Ltd. on the effect of risk perception and risk tolerance on safety behaviors, Ji et al. (2011) observed that risk perception has a direct impact on safety behaviors of airline pilots since the pilots who have a high risk perception adopt safer behaviors than their counterparts with low risk perception. The study also found that the effect of risk tolerance on prevention behaviors is moderated by risk perception: «high risk perception reduced the negative effects of risk tolerance on safety operation behavior, while medium and low risk perception increased the negative effects" (p. 1415). In a study with a population of 320 Ghanaian workers, Gyekye (2006) showed that people who were frequent victims of accidents had a rather negative perception of workplace safety, safety programs, their supervisory staff, and the contributions of their coworkers to safety-related actions. What's more, they were less satisfied with their jobs and got less involved in safety-management programs. In a study addressing the link between perceived risk and behavior among 516 workers from eight different companies, Arezes and Miguel (2008) showed that the higher the perceived risk, the more the workers mentioned wearing hearing protection. In addition, shortly after the nuclear accident at Chernobyl in Ukraine (about a week), Dolinski et al. (1987) found that the Polish who perceived themselves as relatively invulnerable to radioactive diseases were less likely to take precautions than those who felt that they were not more exposed than others. Similarly, in a meta-analysis encompassing 43 studies on links between perceived risk and preventive behaviors, Brewer et al. (2007) showed that perceptions of risk likelihood, as well as feelings of vulnerability and risk seriousness, were variables that significantly predicted prevention behaviors. Finally, in a study in two areas of activity (a chemical factory and a nuclear power plant), Mbaye and Kouabenan (2013) noted that perception of invulnerability and "feeling of control both reduced experiencebased analysis (EBA) motivation for ordinary accidents to a greater extent than for chemical and radiation-related accidents" (p. 310).

These examples of research clearly point out the link between perceived risk and the adoption of preventive attitudes, intentions, and behaviors. However, some studies, albeit somewhat limited in number, show that the results on the relationship between risk perception and self-protective behavior are rather mitigated (Van der Pligt, 1996). In their meta-analysis of the relationship between risk perception and health behavior, Brewer et al. (2007) wrote: "Although the majority of empirical studies find positive associations between risk perceptions and behaviors, as many theories suggest, individual studies report all types of relationships: positive, negative, and none" (p. 136). According to Van der Pligt (1996) who made a literature review on this point, a number of results show that an increased risk perception coupled with a low expectation of success to manage risk, can cause a reaction of powerlessness and decrease intentions to behave appropriately. This is what happens when the recommended preventive behaviors are credited to be relatively ineffective. Some examples of this lack of relationship between risk perception and behavior, is provided about various health problems including smoking cigarette or wearing seatbelts. Concerning this last problem, Stasson and Fishbein (1990) noted that the perception of risk is not directly related to the wearing of seat belts. In addition, Bellrose and Pilisuk (1991) showed that despite their knowledge of the risks inherent in their jobs, specialists in protection against radiation and fire seemed to tolerate them because the management of these risks gives them a certain professional identity, some satisfaction, a rewarding public image, etc. Finally, we can mention the study by Rundmo (2001), which showed that the affective component of risk perception and risk behavior was found to be independent variables while the rational component seemed to have a significant, however small, effect on behavior. Studies on the relationship between risk perception and safety behavior are then still needed.

Even though awareness of a risk does not always trigger selfprotective behavior (Bellrose and Pilisuk, 1991; Stasson and Fishbein, 1990; Van der Pligt, 1996), we can hypothesize that perceived risk is likely to affect risk-related behaviors. Grasping how risk is perceived by first-line managers therefore seems to be important in understanding their efforts (or lack thereof) when it comes to seeing that safety procedures are followed. This study allows us to confirm the existence of a positive relationship between risk perception and behavior, based not on the perception of risk for the self, but the perception of risk to others. Particularly, and this is one of the original features of this study, we examine how the perception of risk for their supervisees could affect the FLMs' involvement in safety management. One can assume, for 
example, that if FLMs think it highly probable that the operators they supervise will experience harmful consequences of certain risks, then these managers will get actively involved in safety management, whereas if they perceive risks as less probable for their supervisees, they will be less motivated to take part in preventive practices. Similarly, one can hypothesize that FLMs' level of involvement will be dependent upon the perceived seriousness of the risk, or even the type of risk. Indeed, as Slovic et al. (1981) stated, "Subjective judgements, whether by experts or lay people, are a major component in any risk assessment. If such judgements are faulty, risk management efforts are likely to be misdirected" (p. 17). We also believe that risk perception and involvement in safety management may be affected by safety climate prevailing in the organization.

\section{Safety climate, safety performance, and involvement in preventive practices}

Zohar (1980) emphasized the importance of the safety climate in how safety is managed within organizations. Safety climate reflects the shared perceptions that have employees of the relative importance granted to safety issues in their organization. These perceptions serve as a frame of reference and provide psychological guidance for choosing adaptive and appropriate workplace behaviors. Assessing the safety climate allows one to find out how workers interpret, evaluate, or judge actions undertaken by managers on safety issues, as well as the importance and value accorded to safety in the organization, the acceptable level of risk, and the attitudes of coworkers toward safety, etc. (Zohar, 1980). "In a study involving employees from about 20 industrial companies, Zohar (1980) shows that the two most important dimensions determining an organization's safety climate are employees' perceptions of the attitude of managers toward safety and their perception of the utility of production-process safety in general. These perceptions and role expectations are likely to influence workplace behaviors and affect the success of safety programs" (Kouabenan, 2001, p. 337).

The safety climate can be grasped by examining perceptions of job conditions and characteristics (Philips et al., 2012; Rysdstedt and Lundh, 2012) and/or by looking at individual attitudes and characteristics (Oliver et al., 2002; Tomas et al., 2011). It may be influenced by leadership style (Zohar and Luria, 2010). Indeed, Zohar and Luria (2010) noted "that supervisory leaders can act as gatekeepers, with transformational leaders offering better protection against potentially harmful organization-level priorities. Furthermore, transformational supervisors better informed their members of the organizational priorities as they perceived them, resulting in a stronger relationship between individual supervisors' perceptions and members' organizational climate perceptions" $\mathrm{p}$. 647). When the climate is defined by individual characteristics the term "psychological climate" is used to encompass: (1) perceived support from supervisors, (2) level of stress generated by one's position and by disharmonious rapports among coworkers and work teams, etc., (3) level of challenge and autonomy involved in the job, and (4) amount of cooperation, friction, and collegiality among members of the work group (Jones et al., 1979). When the climate is defined by organizational characteristics, on the other hand, it is based on structural dimensions of the organization, including formalization of responsibilities, job activities, standardization of procedures, training, disciplinary systems, etc., as well as interdependence between departments, decisions, etc., and centralization of budgetary and policy-related decision-making, and so on (Jones et al., 1979).

The link between safety climate and safety-related performance and attitudes has been widely confirmed. Silva et al. (2004) found a significant relationship between a positive perception of the safety climate and a low accident frequency, while Cooper and Phillips (2004), and then Seo (2005), demonstrated a significant link between positive safety perceptions and pro-safety behaviors among workers. It has been shown in addition that workers are more inclined to address safety issues when their supervisors encourage them to do so, and when their coworkers are also concerned with these issues (Tucker et al., 2008). Workers are also known to be more likely to report safety problems to their supervisors when they are convinced of the effectiveness of prevention programs (Mullen, 2005). Similarly, it has been shown that when workers perceive little use of the data they report to managers, this becomes a source of low commitment to accident-analysis procedures (Pransky et al., 1999). In their study, Arezes and Miguel (2008) noted that the more positively employees viewed the safety climate (perception of the work environment, personal motivation, and physical demands of the job), the more they reported wearing protective hearing gear. Furthermore, Mearns and Yule (2009) showed that the more the high-level managers were perceived as uninterested in safety problems or the well-being of employees, the more the latter tended to take risks and break safety rules. The reverse was also true: the more the managers were perceived as getting involved in safety-related actions and as caring about employees' well-being, the less the latter tended to take risks or violate safety rules. In a meta-analysis, Clarke (2010) showed that "the relationship between safety climate and safety behavior was partially mediated by work-related attitudes (organizational commitment and job satisfaction), and the relationship between safety climate and occupational accidents was partially mediated by both safety behavior and general health" (p. 553). The role of attitude was mentioned also by Tomas et al. (2011) as a mediating variable between safety climate and accident rate. In another meta-analysis, Beus et al. (2010) stated that "injuries were more predictive of organizational safety climate than safety climate was predictive of injuries" (p. 713). They went on to say that "perceived management commitment to safety is the most robust predictor of occupational injuries" (p. 713). In a recent review, Zohar (2010) recommended to address safety climate from a multi-dimensional perspective in order to permit examination of potential interactions between its components which incorporates the relative priorities among the various safety policies, procedures and practices and their competing domains (e.g. productivity or efficiency) in their impact on safety performance. In this sense, Bosak et al. (2013) showed that "employees' risk behavior was negatively related to management commitment to safety and priority of safety and positively related to pressure for production" (p. 256). In the same vein, Vinodkumar and Bhasi (2010) found that management commitment and safety rules and procedures predicted safety compliance directly whereas safety training and safety communication and feedback predicted safety compliance indirectly. Moreover, they found safety training to be the most important safety management practice that predicts safety knowledge, safety motivation, safety compliance and safety participation.

Granted, depending on the approach used, studies on safety climate do not always find a link between safety climate and safety performance. For example, in a critical review of various approaches to safety climate (attitudes, perceptions, etc.), Clarke (2006a) reported that attitudes toward safety did not significantly predict safety performance, whereas perceptions of safety predicted such performance. Moreover, it seems that quantitative indices, such as accident rates, are only weakly linked to safety climate (Siu et al., 2004; Zohar, 2000). In this line, several studies have established a significant link between safety climate and number of self-reported accidents by participants (Hayes et al., 1998), and between safety climate and attitudes about safety (participation and rule-following), although the link between accident 
frequency and safety climate is sometimes rather weak (Clarke, 2006b; Siu et al., 2004; Zohar, 2000). Finally, Huang et al. (2014) showed that only employee safety climate perceptions (and not that of supervisor's) significantly predicted self-reported safety behavior (directly) and objective injury outcomes (indirectly). Despite the inconsistency of the results obtained, owing in part to differing safety climate measures and indicators (Guldenmund, 2007; Mearns et al., 2003), there is nonetheless sufficient proof confirming the impact of safety climate on involvement and participation in safety-related procedures. For this reason, considering this dimension seems to us relevant for examining FLMs involvement in safety management. In doing so, we would particularly be attentive to the nature of the interactions about safety issues between the management and the workers when designing safety climate. Referring to the social exchange theory (Blau, 1964 cited by Hofman and Morgeson (1999)), we also expect that the exchanges between managers and their supervisees concerning safety issues could stimulate their involvement in safety. Indeed, Hofman and Morgeson (1999) showed that exchanges between leaders and group members regarding safety were significantly related to safety communication, safety commitment and accidents. For these authors, "engaging in safety-related communication should be beneficial to both the organization and the employee's leader ..." because "part of the performance evaluation of leaders is the safety record of their subordinates" (p. 293). In our case, we would distinguish between safety-related interactions between FLMS and their immediate supervisors and interactions with their supervisees. Indeed, because of their intermediate position between the executants (workers) and the upper hierarchy, FLMS hold a strategic position in the effective implementation of safety on industrial sites. From this we can suppose that FLMs' perceptions of their supervisees' attitudes exert as much influence on how they picture their role and think they should execute it, as do their perceptions of their supervisors' attitudes regarding safety.

\section{Aims and hypotheses}

The study reported in this article set out to examine the effects of perceived risk and safety climate on involvement in safety management, and to look at the relative weights of each of these two variables. First, we postulated that perceived risk could influence the managerial decisions made by FLMs as well as on the safety-related actions they initiate or encourage. We hypothesize, for example, that if FLMs consider it highly probable that the operators they supervise will experience harmful consequences of certain risks, then these FLMs will get actively involved in safety management, whereas if they perceive risks as less probable for their operators, they will be less motivated to get involved in preventive measures (Hypothesis 1). Secondly, in the light of the studies mentioned above, we assumed that FLMs' perception of the safety climate at their industrial workplace would be related to their involvement in safety management. More specifically, a positive perception of the safety climate should induce strong involvement in safety management, whereas a negative perception should favor low involvement (Hypothesis 2). Moreover, we hypothesized that the effect of safety climate on involvement in safety management would be greater than the effect of perceived risk, and that safety climate would mediate the latter (Hypothesis 3). Finally, we checked whether the various dimensions of the safety climate scale affect differently the mediation of the effect of risk perception on involvement in safety management. In particular, we believed that these dimensions which reflect differently the safety-related interactions and social exchanges between supervisors and supervisees may be differently related to the MPLs involvement in safety management. In this case, we assume that perceived attitude of upper management toward safety, perceived encouragement from immediate supervisors and the feeling of being called upon by supervisees on safety questions would have a different impact on the mediation of the effect of risk perception on involvement in safety management (Hypothesis 4).

\section{Methodology}

\subsection{Study sample}

The participants were 63 first-line managers (FLMs) of two nuclear plants belonging to the French nuclear energy company. They all volunteered to take part in the study and met with researchers at their workplace. They aged between 26 and 57 with an average of 44 years. Their mean number of years of seniority was 20.34, and they supervised 19 operators on average. Among participants, $83.9 \%$ had started at a lower level, that is, they were operators before being promoted to management, while $16.1 \%$ had been hired directly into a management position. Lastly, all of the firm's areas of activity were represented: maintenance (54.1\%), production (21.3\%), logistics $(8.2 \%)$, risk prevention $(8.2 \%)$, and services $(8.2 \%)$. The FLMs in question were foremen of maintenance sites, heads of logistics teams, and managers of technical operations. They had technical and managerial duties, and were required to incorporate safety concerns into their work, specifically through risk assessment, accident analysis, developing and issuing safety instructions, and writing accident reports.

\subsection{Measures}

The study was carried out using a questionnaire made up of several scales of measurement relating to the various variables.

\subsubsection{Measuring safety climate}

The safety climate was assessed using 5-point Likert-type scales ranging from 1 (completely disagree) to 5 (completely agree) with three sub-dimensions: perceived attitude of upper management toward safety, FLMs' feeling of being encouraged by their immediate supervisors to get involved in risk prevention, and the feeling of being called upon by supervisees on safety questions. These last two dimensions reflect the measure of the nature of the interactions or the exchanges as regards safety between managers and their subordinates.

Perceived attitude of upper management toward safety was evaluated using a questionnaire by Zohar and Luria (2004) consisting of 15 statements such as "Our plant's management reacts quickly to resolve safety problems when informed of them" and "Our management takes worker safety into account when planning production pace and work schedules."

For the feeling of being encouraged by one's immediate supervisor, we designed items that invoked (a) the perceived importance that one's immediate supervisor attaches to safety (e.g., "My supervisor gives me clear goals on safety issues", (b) the feeling of being encouraged to get involved (e.g., "My supervisor urges me to find time to take charge of safety procedures"), and (c) perceived support from one's supervisor (e.g., "My supervisor brings in prevention experts to help me").

The items measuring the feeling of being called upon by supervisees on safety issues were designed on the basis of possible interactions that FLMs might experience with operators placed under their supervision and that might motivate them to use their leadership role to better promote safety (e.g., "The operators under my supervision inform me of their desire to participate in developing corrective actions"). 


\subsubsection{Measuring perceived risk}

We assessed FLMs' perception of the hazards that their supervisee's face. This measure is useful insofar as the FLMs are not directly exposed to the risks for which they are responsible but come into contact with them only indirectly, through their supervisees who battle with these risks on a daily basis. We made use of a list of 17 significant risks provided in the firm's Work Health and Safety Report (fall or slip of even foot, radiological contamination, hearing impairment, irradiation, fall from height, fire, explosion, exposure to carcinogens, etc.). First, the FLMs assessed the probability that each of these risks would happen to their operators, on a 6-point Likert-type scale ranging from 0 (not applicable) and 1 (not very probable) on up to 5 (very probable). Then they evaluated the seriousness of these same risks for their operators, on another 6-point scale ranging from 0 (not applicable) and 1 (not very serious) on up to 5 (very serious).

\subsubsection{Measuring involvement in safety management}

To measure involvement in safety management, we designed 28 statements about the extent to which FLMs feel they are being involved in risk-prevention actions by their supervisors or by those responsible for prevention, or about the preventive actions they actually undertake themselves (e.g., "Being involved in accident analysis done in this department", "Participating in prevention plans with contractors"). The FLMs expressed their level of agreement or disagreement with each of the statements on a 5-point Likerttype scale.

\subsection{Procedure}

As stated above, the study was conducted via questionnaire designed by the authors. Participants were contacted through their supervisors who planned the appointments with the researcher for a week on each plant. All first line managers (FLMs) of the two nuclear plants were concerned by the study, but only $70 \%$ actually participated. The remaining $30 \%$ were not able to participate in the study because they were either asked for an urgent intervention at the time of scheduled appointment with the researcher or because they worked the night of the week devoted data collection, or because the researcher did not obtain the necessary accreditation to enter the workplace of some FLMs. The questionnaire was filled out by the FLMs in their office for about $45 \mathrm{~min}$ in the presence of the researcher.

\section{Results}

The data were analyzed using SPSS 20.0 software. We first checked the reliability of our measuring scales (safety climate, perceived risk, involvement in safety management) using a Chronbach's Alpha test. Then we check the relations between the variables using correlation analysis. Lastly, we conducted several mediation analyses to determine whether the effect of perceived risk on involvement in safety management was mediated by perceived safety climate.

\subsection{Preliminary analyses}

All measuring scales obtained a very satisfactory reliability level. This was true for the overall safety climate $(\alpha=.93)$ and for its subdimensions as well: perceived attitude of upper management toward safety $(\alpha=.79)$, feeling of being encouraged by one's immediate supervisor $(\alpha=.90)$, and the feeling of being called upon by supervisees on safety issues $(\alpha=.91)$. The reliability level was also very satisfactory for the measure of perceived risk for operators $(\alpha=.90)$ and for the perceived-risk subdimensions as
Table 1

Means, standard deviations, and reliability of the questionnaire scales.

\begin{tabular}{lllll}
\hline Variable & $N$ & $M$ & SD & $\alpha$ \\
& items & & & \\
\hline Perceived risk & 34 & 2.88 & 1.11 & .90 \\
Perceived probability of risks for operators & 17 & 2.69 & 1.03 & .92 \\
Perceived seriousness of risks for operators & 17 & 3.08 & 1.33 & .96 \\
$\quad$ Safety climate & 50 & 3.32 & .56 & .93 \\
$\quad$ Upper management attitude toward safety & 15 & 3.66 & .47 & .79 \\
$\quad$ Feeling of being encouraged by immediate & 19 & 3.14 & .80 & .90 \\
$\quad$ supervisor & & & & \\
$\quad$ Feeling of being called upon by subordinates on & 16 & 3.15 & .85 & .91 \\
$\quad$ safety issues & & & & \\
$\quad$ Involvement in safety management & 28 & 3.25 & .76 & .91 \\
\hline
\end{tabular}

$N$ items = total number of the items measuring the scale.

well: perceived probability of risk for operators $(\alpha=.92)$ and perceived seriousness of risks for operators $(\alpha=.96)$. Finally, the scale of involvement in safety management showed good internal consistency $(\alpha=.91)$ (see Table 1$)$.

The correlation analysis between the variables yielded significant links between perceived risk and involvement in safety management $(r=.389, p<.01)$, and also between safety climate and involvement in safety management $(r=.757, p<.01)$. The same held true for the subdimensions of safety climate (see Table 2). The correlation between perceived risk and safety climate was significant $(r=.333, p<.05)$. In addition, perceived risk obtained a significant link with two subdimensions of safety climate, namely, the feeling of being encouraged by immediate supervisor $(r=.245$, $p<.05)$ and the feeling of being called upon by supervisees on issues related to safety $(r=.471, p<.001)$.

\subsection{Perceived risk, safety climate, and FLM involvement in safety}

Here, we looked at whether the overall safety climate and its subdimensions were mediators of the relationship between perceived risk and involvement in safety management. For this, we conducted a series of simple linear regression analyses following the Baron and Kenny method $(1986)^{2}$, with involvement in safety management as the predicted variable, perceived risk as the predicting variable, and perceived safety climate and then its subdimensions as mediating variables.

\subsubsection{Perceived risk, overall safety climate, and FLM involvement in safety management}

The results showed that perceived overall safety climate totally mediated the effect of perceived risk on involvement in safety management. ${ }^{3}$ Perceived risk significantly predicted a good safety climate $\left(b=.16, t=2.75, p=.008, R^{2}=.11\right)$ and substantial involvement in safety management $\left(b=.26, t=3.29, p=.002, R^{2}=.15\right)$. This is in line with hypothesis 1 . Likewise, safety climate significantly predicted substantial involvement in safety management $\left(b=1.03, t=9.03, p<.001, R^{2}=.57\right)$, which is consistent with hypothesis 2 . When safety climate was controlled, the effect of perceived risk on safety-management involvement was no longer significant $b=.10, t=1.76, p=.083$ ) (see Fig. 1 ). This result shows that even though perceived risk is related to involvement in

\footnotetext{
2 These authors proposed three steps for confirming a mediation hypothesis: (1) The independent variable (IV) significantly predicts the dependent variable (DV) and the mediating variable (MV). (2) MV significantly predicts DV. (3) When controlling $\mathrm{MV}$, the effect of IV on DV is no longer significant (there is total mediation) or decreases while remaining significant (there is partial mediation). If one of the conditions in steps (1) or (2) is not fulfilled, there is no mediation.

${ }^{3}$ In Fig. 1, as in the various mediation diagrams that follow, the value of beta in parentheses represents the total effect of the IV on the DV, i.e., the effect of IV on DV when MV is not controlled.
} 
Table 2

Correlations between measuring scales.

\begin{tabular}{|c|c|c|c|c|c|c|c|}
\hline Variable & 1 & 2 & 3 & 4 & 5 & 6 & 7 \\
\hline 1. Perceived risk & & & & & & & \\
\hline 2. Perceived probability of risks for operators & $.921^{* *}$ & & & & & & \\
\hline 3. Perceived seriousness of risks for operators & $.953^{* *}$ & $.761^{* *}$ & & & & & \\
\hline 4. Safety climate & $.333^{*}$ & .310 & .314 & & & & \\
\hline 5. Upper management attitude toward safety & -.082 & -.045 & -.101 & $.541^{* *}$ & & & \\
\hline 6. Feeling of being encouraged by immediate supervisor & $.245^{*}$ & .215 & $.242^{*}$ & $.906^{* *}$ & $.447^{* *}$ & & \\
\hline 7. Feeling of being called upon by subordinates & $.471^{* *}$ & $.435^{* *}$ & $.448^{* *}$ & $.815^{* *}$ & .086 & $.594^{* *}$ & \\
\hline 8. Involvement in safety management & $.389^{* *}$ & $.362^{* *}$ & $.366^{* *}$ & $.757^{* * *}$ & $.295^{*}$ & $.622^{* *}$ & $.741^{* * *}$ \\
\hline
\end{tabular}

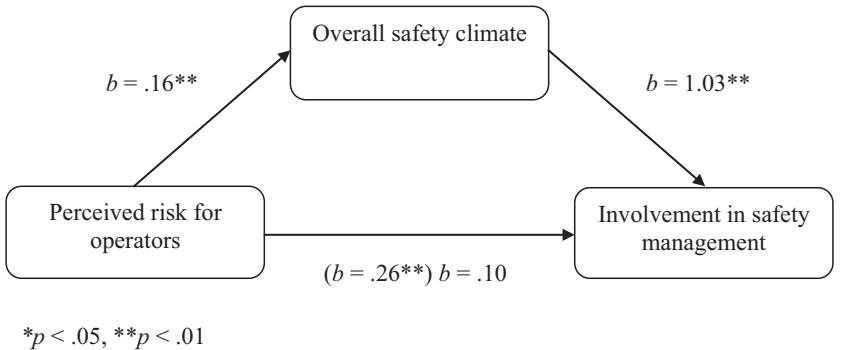

Fig. 1. Mediation test of the effect of perceived risk on involvement on involvement in safety management by overall safety climate.

safety-related behaviors, the effect of safety climate superseded this effect and became a more powerful determinant. This result confirms hypothesis 3.

6.2.2. Perceived risk, perceived attitude of upper management toward safety, and involvement in safety management

The results of the regression analysis did not indicate mediation of the effect of perceived risk on involvement in safety management by upper management's perceived attitude toward safety. Indeed, perceived risk for operators did not significantly predict perceived attitude of upper management toward safety $(b=-.03$, $t=-.63, p=.525$ ).

6.2.3. Perceived risk, feeling of being encouraged by one's immediate supervisor, and involvement in safety management

The results indicated that perceived encouragement from immediate supervisors partially mediated the relationship between perceived risk and involvement in safety management. Specifically, perceived risk predicted perceived encouragement by supervisors ( $b=.17, t=1.97, p=.05, R=.06$ ), which in turn predicted substantial involvement in safety management $(b=.59$, $t=6.20, p<.001, R^{2}=.38$ ). When perceived encouragement by supervisors was controlled, the effect of perceived risk on safetymanagement involvement decreased, but remained significant $\left(b=.17, t=2.53, p=.014, R^{2}=.44\right)$. In other words, perceived encouragement from supervisors did not completely cancel out the effect of perceived risk, which partially explains the involvement of FLMs in safety management (see Fig. 2).

6.2.4. Perceived risk, feeling of being called upon by supervisees, and involvement in safety management

Here, we introduced the feeling of being called upon by supervisees on safety questions as the mediator. This variable totally mediated the effect of perceived risk on involvement in safety management (see Fig. 3). In this case, perceived risk predicted the feeling of being called upon by supervisees $(b=.36, t=4.16$, $p<.001, R^{2}=.22$ ), and this feeling in turn predicted substantial

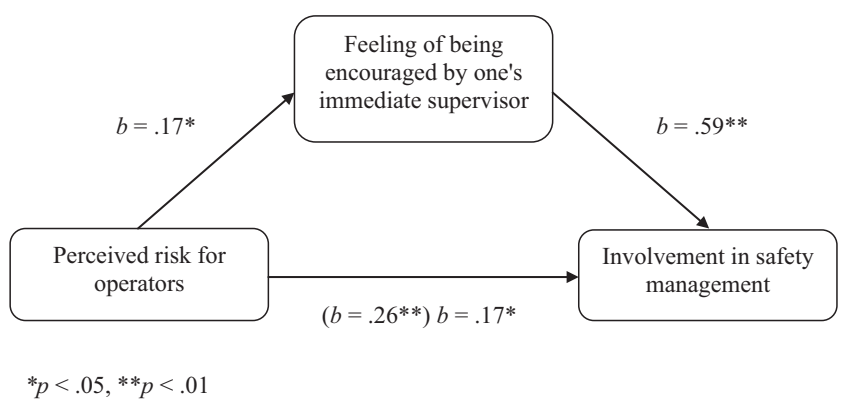

Fig. 2. Mediation test of the effect of perceived risk on involvement in safety management by the feeling of being encouraged by one's immediate supervisor.

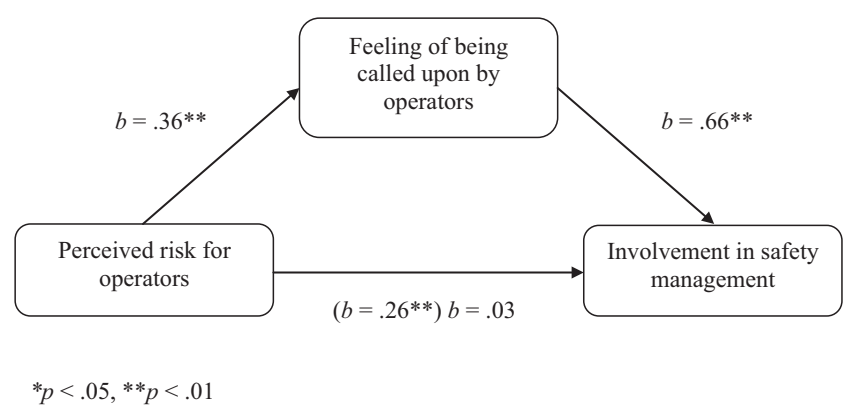

Fig. 3. Mediation test of the effect of perceived risk on involvement in safety management by the feeling of being called upon by one's operators.

involvement in safety management $(b=.66, t=8.62, p<.001$, $\left.R^{2}=.54\right)$. When the feeling of being called upon by supervisees was controlled, the effect of perceived risk on safety-management involvement was no longer significant $(b=.03, t=.52, p=.602)$. These results show that the fact of feeling called upon by operators they supervise in matters of safety, could motivate FLMs to get more involved in promoting safety-related practices than did perceived risk. These last results confirm our hypothesis 4 .

\section{Discussion and conclusion}

As expected, the study results confirmed our hypotheses. Notably, we showed that perceived workplace risk to which firstline managers' supervisees were exposed is positively related to FLMs involvement in safety management. More specifically, the more FLMs perceived that operators under their supervision were exposed to frequent and serious risks the more they got involved in safety management. This first finding corroborates several studies showing that perceived risk positively related to behavior 
(Arezes and Miguel, 2008; Brewer et al., 2007; Gandit et al., 2009; Gyekye, 2006; Kouabenan, 1998, 2009; Kuttschreuter, 2006; Weinstein et al., 2007). It shows that first-line managers' awareness of their supervisees' exposure to risk is a triggering element for their greater concern about safety issues.

In addition, a second main result of our study showed that perception of a good safety climate affected first-line managers' behaviors in the direction of greater involvement in safety-management issues. When the FLMs perceived that a good safety climate prevailed in their workplace, they tended to get more involved in managing safety procedures than when they worked in an environment seen as having a rather poor safety climate. This held true for overall safety climate as well as for each of its subdimensions. The more FLMs perceived that upper management at their plant had a positive attitude toward safety, that their immediate supervisors encouraged them to get involved in preventive actions, and that the operators under their supervision called upon them regularly about safety questions, the more they got involved in safety management. These results align with those observed by various authors (Cooper and Phillips, 2004; Mearns and Yule, 2009; Seo, 2005).

It should be noted, however, that contrary to Zohar (1980), the attitude of upper management toward safety had a lesser effect than did perceived encouragement from immediate supervisor. Thus, like Tucker et al. (2008), we observed that perceived encouragement from immediate supervisors motivated FLMs to get involved in safety-related actions more than did the simple fact that upper management had a positive attitude toward safety. Another important finding comes from the fact that the current study breaks new ground in the sense that it goes beyond upper management and executives to take supervisees' expectations about the role of FLMs into account in assessing the safety climate. It turns out that this third dimension was the one with the greatest relationship with FLMs' involvement in safety management (largest effect size: $b=.66, t=8.62, p<.001, R^{2}=.54$ ). In other words, the FLMs not only needed to feel supported by their supervisors on safety matters, but even more importantly, they were sensitive to being called upon by their supervisees on such matters.

Furthermore, and this is another added value of this study, the mediation analysis demonstrated that the relationship between perceived risk and involvement in safety management was completely mediated by the perceived safety climate. In other words, safety climate seems to be more important than perceived risk in terms of motivating FLM involvement in safety-related actions. Even more interesting is the result showing that being called upon by their supervisee on safety issues was the only subdimension of safety climate that completely mediated the relationship between perceived risk and FLMs' involvement in safety management. This last result lends support to the idea that it is useful to introduce this new dimension into measures of safety climate.

We recognize that our study has some limitations. While the results are interesting, it is difficult to use them in making generalizations. Firstly, the sample size was small, but as we indicated in the procedure, it was difficult to have more in the two nuclear plants subject of the study (70\% of the managers of these industrial sites took part in the study; what represents an appreciable rate of participation nevertheless). Further, we worked with a voluntary sample of first-line managers, not a representative sample of this group. Also, we agree with Grote (2012) that several factors may affect the modes of safety management in high-risk industries. Indeed, our study was conducted at two plants within the nuclear industry, a sector in which safety questions are typically a major concern and garner a great deal of attention. It therefore seems necessary not only to replicate such a study with a larger and more representative sample of first-line managers, but also to do so in another industrial or organizational context.
However, the present study breaks new ground in several areas. To our knowledge, it is one of the first to look at what motivates FLMs to get involved in safety management, and to hypothesize a link between both perceived safety climate and perceived risk as well as to examine the relative weights of each of these two variables. Another important contribution of this study is to include in safety-climate measures the impact of having supervisees call upon FLMs in safety matters. These results shed additional light on how safety climate affects both general safety conditions in organizations and onsite prevention behaviors. In particular, they point to a need to pay attention to a company's safety climate, to encourage and support FLMs by offering them resources to implement the safety procedures they initiate, and by showing them that supervisors appreciate the efforts that front-line managers make in matters of safety. Some safe-behavior models, such as Dejoy's (1996) sequential model of self-protective behavior, posit - and rightfully so - that safety climate is one of the pillars of motivation for triggering the adoption of, and adherence to, safe behaviors. Moreover, the fact that being called upon by supervisees on safety issues very strongly related to FLMs involvement in safety, should provide incentive for organizations to better inform supervisee workers as to what they can expect of their FLMs, and also to urge them to ask questions and make suggestions about safety to their supervisors. This entails creating the conditions for a free and open communication based on trust relationships, excluding possibilities of sanctioning for revelations about safety. Communication and exchange of information seem to be essential for the development of trust and commitment. Indeed, "social exchange builds up feelings of personal obligation, gratitude and trust among partners, all of which lay a foundation of social solidarity" (Chinomona and Moloi, 2014, p.304).

\section{Acknowledgments}

The present study was commissioned and funded by the French company EDF, a producer/distributor of electricity.

\section{References}

Ajzen, I., 2001. Nature and operation of attitudes. Annu. Rev. Psychol. 52, 27-58. http://dx.doi.org/10.1146/annurev.psych.52.1.27.

Arezes, P.M., Miguel, A.S., 2008. Risk perception and safety behaviour: a study in an occupational environment. Saf. Sci. 46 (6), 900-907. http://dx.doi.org/10.1016/ j.ssci.2007.11.008.

Baron, R.M., Kenny, D.A., 1986. The moderator-mediator variable distinction in social psychological research: conceptual, strategic and statistical considerations. J. Personal. Soc. Psychol. 51 (6), 1173-1182. http://dx.doi.org/ 10.1037/0022-3514.51.6.1173.

Bellrose, C.A., Pilisuk, M., 1991. Vocational risk tolerance and perceptions of occupational hazards. Basic Appl. Soc. Psychol. 12 (3), 303-323. http:// dx.doi.org/10.1207/s15324834basp1203_5.

Beus, J.M., Payne, S.C., Bergman, M.E., Arthur Jr., W., 2010. Safety climate and injuries: an examination of theoretical and empirical relationships. J. Appl. Psychol. 95 (4), 713-727. http://dx.doi.org/10.1037/a0019164.

Bosak, J., Coetsee, W.J., Cullinane, S.-J., 2013. Safety climate dimensions as predictors for risk behavior. Accident Anal. Prevent. 55, 256-264. http:// dx.doi.org/10.1016/j.aap.2013.02.022.

Brewer, N.T., Chapman, G.B., Gibbons, F.X., Gerrard, M., McCaul, K.D., Weinstein, N.D., 2007. Meta-analysis of the relationships between risk perception and health behavior: the example of vaccination. Health Psychol. 26 (2), 136-145. http://dx.doi.org/10.1037/0278-6133.26.2.136.

Chinomona, E., Moloi, K.C., 2014. The role played by institutional support in the commitment, job satisfaction and employee performance of teachers in Gauteng province of South Africa: a social exchange perspective. Mediterranean J. Social Sci. 5 (2), 303-315.

Clarke, S., 2006a. The relationship between safety climate and safety performance. A meta-analytical review. J. Occup. Health Psychol. 11 (4), 315-327. http:// dx.doi.org/10.1037/1076-8998.11.4.315.

Clarke, S., 2006b. Contrasting perceptual, attitudinal and dispositional approaches to accident involvement in the workplace. Saf. Sci. 44 (6), 537-550. http:// dx.doi.org/10.1016/j.ssci.2005.12.001.

Clarke, S., 2010. An integrative model of safety climate: linking psychological climate and work attitudes to individual safety outcomes using meta-analysis. J. 
Occup. Organisational Psychol. 83 (3), 553-578. http://dx.doi.org/10.1348/ $096317909 \times 452122$.

Cooper, M.D., Phillips, R.A., 2004. Exploratory analysis of the safety climate and safety behaviour relationship. J. Safe. Res. 35 (5), 497-512. http://dx.doi.org/ 10.1016/j.jsr.2004.08.004.

Dejoy, D.M., 1996. Theoretical model of health behaviour and work-place self protective behaviour. J. Safe. Res. 27 (2), 62-72. http://dx.doi.org/10.1016/00224375(96)00007-2.

Dolinski, D., Gromski, W., Zawisza, E., 1987. Unrealistic pessimism. J. Social Psychol. 12, 511-516.

Gandit, M., Kouabenan, D.R., Caroly, S., 2009. Road-tunnel fires: risk perception and management strategies among users. Safe. Sci. 47, 105-114. http://dx.doi.org/ 10.1016/j.ssci.2008.01.001.

Grote, G., 2012. Safety management in different high-risk domains - all the same? Safe. Sci. 50, 1983-1992. http://dx.doi.org/10.1016/j.ssci.2011.07.017.

Guillaume, O., Gillet, A., 2009. L'encadrement intermédiaire: Une revue de la littérature sociologique commentée (Research Report No. H-T54-2009-00305FR), EDF, Paris.

Guldenmund, F.W., 2007. The use of questionnaires in safety culture research - an evaluation. Safe. Sci. 45 (6), 723-743. http://dx.doi.org/10.1016 j.ssci.2007.04.006.

Gyekye, S.A., 2006. Workers' perception of workplace safety: an African perspective Int. J. Occup. Safe. Ergonomics 12 (1), 31-42 (<http://www.ciop.pl/16245>)

Hayes, B.E., Perander, J., Smecko, T., Trask, J., 1998. Measuring perceptions of workplace safety: development and validation of the work safety scale. J. Safe. Res. 29 (3), 145-161. http://dx.doi.org/10.1016/S0022-4375(98)00011-5.

Hofman, D.A., Morgeson, F.P., 1999. Safety-related behavior as a social exchange: the role of perceived organizational support and leader-member exchange. J. Appl. Psychol. 84 (2), 286-296.

Huang, Y.-H., Robertson, M.M., Lee, J., Rineer, J., Murphy, L.A., Garabet, A., Dainoff, M.J., 2014. Supervisory interpretation of safety climate versus employee safety climate perception: association with safety behavior and lone workers. Transport. Res. Part F. http://dx.doi.org/10.1016/j.trf.2014.04.006.

Ji, M., You, X., Lan, J., Yang, S., 2011. The impact of risk tolerance, risk perception and hazardous attitude on safety operation among airline pilots in China. Safe. Sci. 49, 1412-1420. http://dx.doi.org/10.1016/j.ssci.2011.06.007.

Jones, A.P., James, L.R., Bruni, J.R., Hornick, C.W., Sells, S.B., 1979. Psychological climate: dimensions and relationships of individual and aggregated work environment perceptions. Organizational Behav. Human Perform. 23 (2), 201 250. http://dx.doi.org/10.1016/0030-5073(79)90056-4.

Kouabenan, D.R., 1998. Beliefs and the perception of risks and accidents. Risk Anal., Int. J. 18 (3), 243-252. http://dx.doi.org/10.1111/j.1539-6924.1998.tb01291.x.

Kouabenan, D.R., 2001. Culture, perception des risques et explication des accidents. Bull. Psychol. 54 (3), 327-342.

Kouabenan, D.R., 2006. Psychologie du risque ou pourquoi étudier la perception et l'évaluation du risque? In: Kouabenan, D.R., Cadet, B., Hermand, D., Muñoz Sastre, M.T. (Eds.), Psychologie du risque: Identifier, évaluer, prévenir, Bruxelles, De Boeck, pp. 7-15.

Kouabenan, D.R., 2009. Role of beliefs in accident and risk analysis and prevention. Safe. Sci. 47, 767-776. http://dx.doi.org/10.1016/j.ssci.2008.01.010.

Kouabenan, D.R., Dubois, M., Scarnato, F., De Gaudemaris, R., Mallaret, M.R., 2007. Methicillin-resistant staphylococcus aureus risk perception by healthcare personnel in a public hospital. Soc. Behav. Personal. 35 (1), 89-100. http:// dx.doi.org/10.2224/sbp.2007.35.1.89.

Kuttschreuter, M., 2006. Psychological determinants of reactions to food risk messages. Risk Anal. 26 (4), 1045-1057. http://dx.doi.org/10.1111/j.15396924.2006.00799.x.

Mbaye, S., Kouabenan, D.R., 2013. Effects of the feeling of invulnerability and the feeling of control on motivation to participate in experience-based analysis, by type of risk. Accident Anal. Prevent. 51, 310-317. http://dx.doi.org/10.1016 j.aap.2012.11.026.

Mearns, K., Yule, S., 2009. The role of national culture in determining safety performance: challenges for the global oil and gas industry. Safe. Sci. 47 (6), 777-785. http://dx.doi.org/10.1016/j.ssci.2008.01.009.

Mearns, K., Whitaker, S.M., Flin, R., 2003. Safety climate, safety management practice and safety performance in offshore environments. Safe. Sci. 41 (8), 641-680. http://dx.doi.org/10.1016/S0925-7535(02)00011-5.
Mullen, J., 2005. Testing a model of employee willingness to raise safety issues. Can. J. Behav. Sci. 37 (4), 273-282. http://dx.doi.org/10.1037/h0087262.

O'Dea, A., Flin, R., 2001. Site managers and safety leadership in the offshore oil and gas industry. Safe. Sci. 37 (1), 39-57. http://dx.doi.org/10.1016/S09257535(00)00049-7.

Oliver, A., Cheyne, A., Tomás, J.M., Cox, S., 2002. The effects of organizational and individual factors on occupational accidents. J. Occup. Organizational Psychol. 75 (4), 473-488. http://dx.doi.org/10.1348/096317902321119691.

Philips, D.L., Malley, C., Ashcroft, D.M., 2012. Job characteristics and safety climate: the role of effort-reward and demand-control-support models. J. Occup. Health Psychol. 17 (3), 279-289. http://dx.doi.org/10.1037/a0028675.

Pransky, G., Snyder, T., Dembe, A., Himmelstein, J., 1999. Under-reporting of workrelated disorders in the workplace: a case study and review of the literature. Ergonomics 42 (1), 171-182. http://dx.doi.org/10.1080/001401399185874.

Rundmo, T., 2001. Employee images of risk. J. Risk Res. 4 (4), 393-404, doi: 1080/ 136698701100653259.

Rysdstedt, L.W., Lundh, M., 2012. The relationship between psychological working conditions and perceived safety climate for engine room officers in the Swedish merchant fleet. Sociol. Study 2 (1), 42-48.

Seo, D.-C., 2005. An explicative model of unsafe work behaviour. Safe. Sci. 43 (3), 187-211. http://dx.doi.org/10.1016/j.ssci.2005.05.001.

Silva, S., Lima, M.L., Baptista, C., 2004. OSCI: an organizational and safety climate inventory. Safe. Sci. 42 (3), 205-220. http://dx.doi.org/10.1016/S09257535(03)00043-2.

Siu, O., Phillips, D.R., Leung, T., 2004. Safety climate and safety performance among construction workers in Hong Kong: the role of psychological strains as mediators. Accident Anal. Prevent. 36 (3), 359-366. http://dx.doi.org/10.1016/ S0001-4575(03)00016-2.

Slovic, P., Fischhoff, B., Lichtenstein, S., 1981. Perceived risk: psychological factors and social implications. Proc. R. Soc. London 376 (1764), 17-34. http:// dx.doi.org/10.1098/rspa.1981.0073.

Stasson, M., Fishbein, M., 1990. The relation between perceived risk and preventive action: a within-subject analysis of perceived driving risk and intentions to wear seatbelts. J. Appl. Soc. Psychol. 20 (19), 1541-1557. http://dx.doi.org/ 10.1111/j.1559-1816.1990.tb01492.x.

Tomas, J.M., Cheyne, A., Oliver, A., 2011. The relationship between safety attitudes and occupational accidents. The role of safety climate. Eur. Psychol. 16 (3), 209219. http://dx.doi.org/10.1027/1016-9040/a000036.

Tucker, S., Chmiel, N., Turner, N., Hershcovis, M.S., Stride, C.B., 2008. Perceived organizational support for safety and employee safety voice: the mediating role of co-worker support for safety. J. Occup. Health Psychol. 13 (4), 319-330. http://dx.doi.org/10.1037/1076-8998.13.4.319.

Van der Pligt, J., 1996. Risk perception and self-protective behavior. Eur. Psychol. 1 (1), 34-43. http://dx.doi.org/10.1027/1016-9040.1.1.34.

Vinodkumar, M.N., Bhasi, M., 2010. Safety management practices and safety behavior: assessing the mediating role of safety knowledge and motivation. Accident Anal. Prevent. 42, 2082-2093. http://dx.doi.org/10.1016/ j.aap.2010.06.021.

Weinstein, N.D., Kwitel, A., McCaul, K.D., Magan, R.E., Gerrard, M., Gibbons, F.X., 2007. Risk perception: assessment and relationship to influenza vaccination Health Psychol. 26 (2), 146-151. http://dx.doi.org/10.1037/02786133.26.2.146.

Zohar, D., 1980. Safety climate in industrial organizations: theoretical and applied implications. J. Appl. Psychol. 65 (1), 96-102. http://dx.doi.org/10.1037/00219010.65.1.96.

Zohar, D., 2000. A group-level model of safety climate: testing the effect of group climate on micro-accidents in manufacturing jobs. J. Appl. Psychol. 85 (4), 587596. http://dx.doi.org/10.1037/0021-9010.85.4.587.

Zohar, D., 2010. Thirty years of safety climate research: reflections and future directions. Accident Anal. Prevent. 42, 1517-1522.

Zohar, D., Luria, G., 2004. Climate as a social-cognitive construction of supervisory safety practices: scripts as proxy of behaviour patterns. J. Appl. Psychol. 89 (2), 322-333. http://dx.doi.org/10.1037/0021-9010.89.2.322.

Zohar, D., Luria, G., 2010. Group leaders as gatekeepers: testing safety climate variations across levels of analysis. Appl. Psychol.: Int. Rev. 59 (4), 647-673. http://dx.doi.org/10.1111/j.1464-0597.2010.00421.x. 